\title{
PERFIL DE TEXTURA E COMPOSIÇÃO DE HAMBÚRGUERES ELABORADOS COM DIFERENTES TEORES DE GORDURA E PLASMA SANGUÍNEO BOVINO
}

\author{
Fabio Batista Claudino', William Bertoloni
}

1 UFMT

Correspondência: Fabio Batista Claudino: fabio.claudino@gmail.com

RESUMO: Com o intuito de pesquisar a influência da proteína plasmática na qualidade sensorial de hambúrgueres de carne bovina, avaliou-se a adição de plasma de sangue bovino $(0 \%, 5 \%$ e $10 \%)$ nas características de força de cisalhamento, perfil de textura e análise sensorial associado a três níveis de gordura $(5 \%, 10 \%$ e $17 \%)$. Obteve-se redução $(p<0,05)$ na dureza $(9528,63 \mathrm{~g})$, mastigabilidade $(5683,50 \mathrm{~g} . \mathrm{s})$ e gomosidade $(6634,65 \mathrm{~g})$ ao se utilizar $5 \%$ de plasma e $10 \%$ de gordura. Na ausência de plasma a redução da gordura de 17\% para $10 \%$ elevou $(p<0,05)$ os valores de dureza $(10070,08 \mathrm{~g})$, mastigabilidade $(5996,27 \mathrm{~g} . \mathrm{s})$ e gomosidade $(7040,23 \mathrm{~g})$. Observou-se redução $(p<0,05)$ na força de cisalhamento $(2211,83 \mathrm{~g})$ ao se utilizar $10 \%$ de plasma com $5 \%$ de gordura, entretanto a analise sensorial para dureza não apresentou diferenças entre tratamentos. Conclui-se que a proteína plasmática têm potencial para ser utilizada como substituinte de gordura em hambúrgueres e que as respostas do perfil de textura, força de cisalhamento e analise sensorial dependem de combinação entre as quantias de gordura e plasma utilizados.

Palavras-chave: proteínas; maciez; rendimento; substituto

\section{TEXTURE PROFILE AND COMPOSITION OF HAMBURGERS PREPARED WITH DIFFERENT LEVELS OF FAT AND BEEF BLOOD PLASMA}

\begin{abstract}
As the aim to investigate the effect of plasma protein on the sensory quality of beef hamburger was evaluated addition of bovine serum samples $(0 \%, 5 \%$ and $10 \%)$ in the shear force characteristics, texture profile and analysis sensory associated with three fat levels $(5 \%, 10 \%$ and $17 \%)$.

Was obtained a reduction $(p<0.05)$ in hardness $(9528.63 \mathrm{~g})$, chewiness $(5683.50 \mathrm{~g} . \mathrm{s})$ and gumminess $(6634.65 \mathrm{~g})$ when using $5 \%$ plasma and $10 \%$ fat. In the absence of plasma fat reduction from $17 \%$ to $10 \%$ increased $(p<0.05)$ hardness values $(10070.08 \mathrm{~g})$, chewiness $(5996.27 \mathrm{~g} . \mathrm{s})$ and gumminess $(7040.23 \mathrm{~g})$. Reduction was observed $(\mathrm{p}<0.05)$ in shear force $(2211.83 \mathrm{~g})$ when using $10 \%$ plasma with $5 \%$ fat, however, the sensory analysis for hardness did not differ between treatments. We conclude that plasma proteins have the potential to be used as a substitute for fat in burgers and that the responses of texture profile, shear force and sensory analysis depend on combination between the amounts of fat and plasma used.
\end{abstract}

Key Words: proteins; softness; yield; replacement 

gordura e plasma sanguíneo bovino

\section{INTRODUÇÃO}

O aumento da ocorrência de doenças associadas ao elevado consumo de gorduras tem proporcionado a procura por alimentos com teores reduzidos de lipídeos, entretanto a redução dos teores promove alterações de sabor, aroma e textura nos alimentos nem sempre aceitas pelos consumidores (Vandendriessche, 2008; Keeton, 1994; Jiménez-Colmenero, 1996).

Para se minimizar tais prejuízos, são necessários ajustes na formulação dos produtos através da utilização de aditivos que mimetizem as propriedades tecnológicas da gordura.

Alguns substituintes de gordura, como o plasma sanguíneo podem aumentar a capacidade de retenção de água de formulações com baixos teores de gordura e manter a palatabilidade desejada (Troy, Desmond e Buckley 1999).

possui propriedades tecnológicas comparáveis à albumina do ovo e proteínas do soro do leite (Crenwelge et al., 1974) basicamente composto por proteínas $(7 \%)$, água $(91 \%)$ e sais minerais (1\%) (Del Hoyo, Rendueles e Díaz, 2008), entretanto no Brasil a grande maioria do plasma proveniente dos abates é descartado e pequena parte é aproveitado para fins tecnológicos, o que gera desperdício e sobrecarrega as redes de tratamento de efluente por ser uma fonte poluidora (Penteado et al., 1979).

A formação de géis estáveis através de indução térmica é uma das principais propriedades das proteínas plasmáticas, que, segundo Saguer et al. (2009), é um evento complexo, composto por várias etapas e dependente de fatores como $\mathrm{pH}$, temperatura e tempo. Esta propriedade permite o seu uso como substituinte de gordura já que no processo de gelificação a matriz protéica formada prende a água adicionada aos ingredientes da formulação e suas propriedades reológicas são alteradas à medida que ocorre a agregação protéica durante a formação da matriz (Tobitani e Ross-Murphy, 1997).

Proteínas plasmáticas de sangue bovino têm sido avaliadas experimentalmente como substituintes de gordura em produtos cárneos com o objetivo de melhoria do rendimento, redução de custos, manutenção das propriedades nutricionais, melhoria das propriedades funcionais (capacidade de retenção de água) e redução dos teores de colesterol associados à gordura (Abiola e Adegbaju, 2001), entretanto poucos estudos referentes a utilização de plasma em hambúrgueres são encontrados na literatura cientifica.

O objetivo deste trabalho foi avaliar a influência da aplicação de proteínas plasmáticas no perfil de textura de hambúrgueres associados a diferentes níveis de gordura em sua formulação.

\section{MATERIAL E MÉTODOS}

Após a limpeza, cortes da paleta ( $T$. brachii) e gordura do peito $(P$. profundus) de bovinos Nelore, foram moídos separadamente em disco de 3,0 $\mathrm{mm}$ com auxílio de moedor da marca Poli Modelo PCP-10L, Potência0,5CV/368W. Em seguida, os cortes e o plasma foram misturados em proporções adequadas para se obter 0 percentual de gordura $(17 \%, 10 \%$ e $5 \%)$ e de plasma sanguíneo ( $0 \%, 5 \%$ e $10 \%)$ de acordo com os tratamentos, assim como água, sal, fosfato, eritorbato de sódio e cebola em pó (Tabela 1).

Os hambúrgueres foram moldados manualmente com peso de $50 \mathrm{~g}$, congelados a $-18^{\circ} \mathrm{C}$ em congelador contínuo (FMC FoodTech) tipo linear com um tempo de congelamento de 2,5 min., acondicionados em embalagens 
de polietileno em atmosfera normal e armazenados em câmara de congelamento durante 3 dias até 0 momento das análises.

Tabela 1 - Tratamentos utilizados nos experimentos

\begin{tabular}{ccccccc}
\hline Tratamento & Gordura & Plasma & Água & $\begin{array}{c}\text { Carne } \\
\text { Magra }\end{array}$ & Tempero & Total \\
\hline T1 & \multirow{2}{*}{$17 \%$} & $0,00 \%$ & $10,00 \%$ & $72,00 \%$ & $3,00 \%$ & $100,00 \%$ \\
T2 & $5,00 \%$ & $5,00 \%$ & $72,00 \%$ & $3,00 \%$ & $100,00 \%$ \\
T3 & & $10,00 \%$ & $0,00 \%$ & $72,00 \%$ & $3,00 \%$ & $100,00 \%$ \\
& & & & & & \\
T4 & \multirow{2}{*}{$10 \%$} & $5,00 \%$ & $15,00 \%$ & $72,00 \%$ & $3,00 \%$ & $100,00 \%$ \\
T5 & & $10,00 \%$ & $10,00 \%$ & $72,00 \%$ & $3,00 \%$ & $100,00 \%$ \\
T6 & & & & $72,00 \%$ & $3,00 \%$ & $100,00 \%$ \\
T7 & & $0,00 \%$ & $20,00 \%$ & $72,00 \%$ & $3,00 \%$ & $100,00 \%$ \\
T8 & $5 \%$ & $5,00 \%$ & $15,00 \%$ & $72,00 \%$ & $3,00 \%$ & $100,00 \%$ \\
T9 & & $10,00 \%$ & $10,00 \%$ & $72,00 \%$ & $3,00 \%$ & $100,00 \%$
\end{tabular}

O plasma sanguíneo comercial, foi obtido por centrifugação a partir do sangue coletado de maneira asséptica diretamente da artéria aorta de bovinos rastreados, abatidos em frigoríficos controlados pelo Serviço de Inspeção Federal (SIF) e liberados para 0 consumo humano, obedecendo os artigos 147 e 4317 do RIISPOA e circular n68/DICAR/BR de 20/12/78 que regula a utilização de sangue bovino em embutidos cozidos. O plasma foi transportado congelado a $-18^{\circ} \mathrm{C} \mathrm{em}$ embalagem de polietileno de $30 \mathrm{~kg}$ e assim permaneceu até o momento do seu uso.

Análises químicas foram realizadas nos hambúrgueres crus descongelados, a determinação de proteína bruta foi realizada baseando-se no método de combustão (AOAC, 2007a) utilizando-se o determinador de proteína Leco (modelo FP-528), o teor de lipídeos foi determinado pelo método Soxhlet (AOAC, 2007b), a porcentagem de umidade pelo método de perda de água e substâncias voláteis (AOAC, 2007c), a determinação de sal ( $\mathrm{NaCl}$ ) foi realizada por titulação argentométrica segundo o método de Mohr (BRASIL 1999), a porcentagem de cinzas foi determinada utilizando-se 0 método gravimétrico (AOAC, 2007d).

Os hambúrgueres congelados ($12^{\circ} \mathrm{C}$ ) foram cozidos em grill da marca George Foreman modelo GBZ38 com seletor de temperatura. As peças foram submetidas à temperatura de $160^{\circ} \mathrm{C}$ durante 6 minutos sendo 3 minutos de cada lado e permaneceram no grill até atingir $70^{\circ} \mathrm{C}$, monitorado por termopares tipo $\mathrm{T}$ (Constantan-Cobre) localizados no centro geométrico dos hambúrgueres.

A Análise do Perfil de Textura ou TPA (Texture Profile Analysis) foi realizada utilizando-se texturômetro TAXT2 (Stable Micro Systems). Para a análise, as amostras de hambúrguer fritas foram cortadas em cilindros de 2,5 $\mathrm{cm}$ de diâmetro e 1,0 cm de altura. Os pedaços foram submetidos a uma carga de compressão de $50,0 \mathrm{~kg}$ a uma distância de 50,0mm através de um probe cilíndrico de alumínio de $25 \mathrm{~mm}$ de diâmetro.

A análise da força de cisalhamento foi realizada utilizando-se o probe Warner-Bratzler. Efetuou-se o corte no sentido transversal das amostras de hambúrguer frito de forma a se obter paralelogramos de 2,5 $\times 2,5 \times$ $1,0 \mathrm{~cm}$. Os paralelogramos foram submetidos à lâmina Warner-Bratzler para a mensuração da força de cisalhamento, utilizando-se para isso o texturômetro TA-XT2 (Stable Micro Systems).

Para a análise sensorial foi aplicado o teste de comparação múltipla utilizado para determinar a diferença do controle de uma ou mais amostras quanto a um atributo específico, no caso a dureza. Foi avaliada a diferença somente entre os tratamentos com 0 menor teor de gordura (5\%). Para isso foram utilizados 26 provadores não treinados, selecionados entre os alunos da Universidade Federal de Mato Grosso (UFMT). Este recebiam 3 amostras codificadas, mais a amostra controle, sendo que uma das amostras codificadas era igual ao controle. Os provadores, em cabines sensoriais apropriadas, classificavam as amostras codificadas em relação ao controle 

gordura e plasma sanguíneo bovino

utilizando uma escala de grau de diferença, sendo 1 para nenhuma diferença e 5 para extrema diferença. Os hambúrgueres foram servidos quentes $\left(\sim 40^{\circ} \mathrm{C}\right)$ e preparados previamente no grelhador George Foreman modelo GBZ2. As peças de hambúrguer foram cortadas em 4 partes para serem servidas.

O delineamento experimental utilizado foi o inteiramente casualizado. Utilizou-se a análise de variância (ANOVA) e o teste Tukey $(p \leq 0,05)$ para os tratamentos compostos por três níveis de gordura e três níveis de plasma

Foram delineados para cada análise nove tratamentos com oito repetições, em um total de 72 parcelas, sendo que cada hambúrguer representou uma parcela. A análise estatística foi realizada com o auxílio do programa estatístico MINITAB Release 16 for Windows $\AA$.

\section{RESULTADOS E DISCUSSÃO}

Observa-se na Tabela 2 que a dureza permaneceu constante para os tratamentos com $17 \%$ de gordura e 0, 5 e $10 \%$ de plasma (T1, T2 e T3), independentemente da quantidade de plasma adicionado $(p>0,05)$. Houve redução significativa $(p<0,05)$ da dureza nos formulações contendo $10 \%$ gordura e ausência ou adição de $5 \%$ de plasma (T4 e T5). Os resultados foram diferentes do esperado para os tratamentos com $5 \%$ de gordura e 0,5 e $10 \%$ de plasma (T7, T8 e T9), pois nos tratamentos contendo $5 \%$ de plasma ou ausência de plasma ocorreu aumento da dureza $(p<0,05)$ e entre T8 ( $5 \%$ de plasma) e T9 (10\% de plasma) a dureza reduziu significativamente $(p<0,05)$. Esperava-se, neste caso, que houvesse uma redução progressiva da dureza com aumento da concentração do plasma o que se apresentou foi o aumento da dureza ao se utilizar $5 \%$ e redução com $10 \%$ de plasma. Este fenômeno está associado à saturação da capacidade da matriz protéica em reter umidade, demonstrando a existência de um ponto ótimo das proteínas se ligarem à água. Duarte e Sgarbieri (2000) determinaram a quantidade máxima de água absorvida pelo concentrado protéico de plasma indicando um limite de saturação, entretanto neste estudo o limite foi determinado em um sistema sem a interferência de outras proteínas. Kumar e Sharma (2004) relatam que há uma proporção ótima entre a adição de água e a adição do substituinte de gordura para que seja efetiva sua atuação.

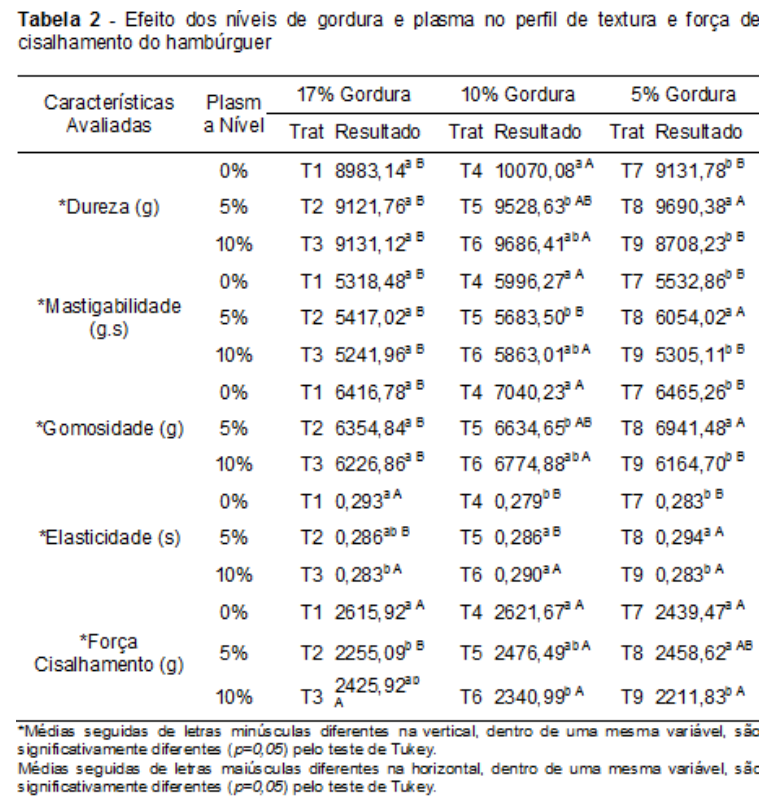

Os resultados na literatura ainda são controversos, Guzman et al. (1995) não encontram diferenças na dureza ou coesividade em hambúrgueres contendo de $1,5 \%$ a $3,5 \%$ de proteínas plasmáticas, Viana et al. (2005) encontraram redução da dureza utilizando plasma e globina como substituinte de gordura em patê de presunto.

Reduzindo-se a concentração de gordura (Tabela 2), dentro de cada nível de plasma observou-se aumento da dureza $(p<0,05)$ entre os tratamentos 
T1 17\% gordura e ausência de plasma) e T4 $(10 \%$ gordura e ausência de plasma), indicando maior interação entre as proteínas durante o cozimento o que pode ter resultado no aumento da força para se deformar o hambúrguer. Troy, Desmond e Buckley (1999) relatam maior interação proteínaproteína em produtos de alta concentração deste nutriente, como é o caso do tratamento $\mathrm{T} 4$.

$$
\text { Observou-se (Tabela }
$$

diferenças significativas $(p<0,05)$ na concentração da proteína total entre $\mathrm{T} 1(14,48 \pm 0,48 \%)$ e $\mathrm{T} 4(16,04 \pm 0,22 \%)$, assim como nas concentrações de gordura $\quad \mathrm{T} 1(17,78 \pm 0,42 \%) \quad \mathrm{e}$ T4(10,48 $\pm 0,26 \%)$ o que contribuiu para a diferença nos valores de dureza avaliados. Wong e Maga (1995) relataram maior maciez em hambúrgueres com teores de gordura de $12 \%$ e $20 \%$ em comparação a $4 \%$ demonstrando a ação positiva da gordura na maciez do produto, corroborando com os resultados do presente estudo.

\begin{tabular}{|c|c|c|c|c|c|}
\hline Tratamento & $\begin{array}{l}\text { *Proteína } \\
\text { Total (\%) }\end{array}$ & $\begin{array}{l}\text { *Lipideos } \\
\text { Totais (\%) }\end{array}$ & ${ }^{*}$ Umidade $(\%)$ & ${ }^{*} \operatorname{Cinzas}(\%)$ & ${ }^{*}$ Sal (\%) \\
\hline T1 & $14,48 \pm 0,48^{\mathrm{e}}$ & $17,78 \pm 0,42^{\mathrm{a}}$ & $66,54 \pm 1,07^{\circ}$ & $2,61 \pm 0,04^{0}$ & $1,32+0,06^{\mathrm{ab}}$ \\
\hline $\mathrm{T} 2$ & $14,59 \pm 0,92^{\mathrm{e}}$ & $17,66 \pm 0,44^{\mathrm{a}}$ & $66,29 \pm 1,18^{\natural}$ & $2,71 \pm 0,01^{\mathrm{ab}}$ & $1,29 \pm 0,05^{\circ}$ \\
\hline T3 & $15,02 \pm 0,43^{\text {be }}$ & $17,58 \pm 0,43^{\mathrm{a}}$ & $65,50 \pm 1,66^{6}$ & $2,76 \pm 0,13^{a b}$ & $1,31 \pm 0,07^{\mathrm{a}}$ \\
\hline $\mathrm{T} 4$ & $16,04 \pm 0,22^{\text {ors }}$ & $10,48 \pm 0,26^{\circ}$ & $69,85 \pm 0,20^{\text {bos }}$ & $2,65 \pm 0,03^{\circ}$ & $1,40 \pm 0,03^{\mathrm{a}}$ \\
\hline T5 & $15,76 \pm 0,03^{\text {ss }}$ & $10,39 \pm 0,30^{\circ}$ & $70,57 \pm 1,50^{3005}$ & $2,94 \pm 0,09^{\mathrm{a}}$ & $1,44 \pm 0,09^{\mathrm{a}}$ \\
\hline T6 & $15,37 \pm 0,06$ ose & $10,25 \pm 0,25^{\circ}$ & $67,55 \pm 5,36^{\infty \triangleleft}$ & $2,84 \pm 0,01^{3 \mathrm{D}}$ & $1,48 \pm 0,01^{\mathrm{at}}$ \\
\hline $\mathrm{T} 7$ & $16,33 \pm 0,14^{\circ \mathrm{c}}$ & $5,08 \pm 0,15^{\circ}$ & $74,47 \pm 1,43^{\mathrm{ab}}$ & $2,71 \pm 0,06^{a b}$ & $1,51 \pm 0,11^{\mathrm{a}}$ \\
\hline T8 & $16,98 \pm 0,03^{\mathrm{ab}}$ & $5,01 \pm 0,14^{\circ}$ & $75,20 \pm 0,27^{\mathrm{a}}$ & $2,75 \pm 0,02^{3 \mathrm{~b}}$ & $1,47 \pm 0,10^{38}$ \\
\hline T9 & $17,47 \pm 0,22^{\mathrm{a}}$ & $4,98 \pm 0,17^{\circ}$ & $74,25 \pm 0,94^{\mathrm{ab}}$ & $2,80 \pm 0,21^{a b}$ & $1,46 \pm 0,10^{\mathrm{a}}$ \\
\hline
\end{tabular}

Observou-se redução significativa da dureza entre T4 (10\% de gordura) e T7 (5\% de gordura) na ausência do plasma (Tabela 2), indicando maior incorporação da água adicionada à formulação, adicionando-se $5 \%$ de plasma observou-se aumento significativo $(p<0,05)$ na dureza ao se reduzir a gordura entre os tratamentos T2 (17\% de gordura) e T8 (5\% de gordura). Utilizando $10 \%$ de plasma, observou-se que a dureza aumentou significativamente entre T3 $(17 \%$ de gordura) e T6 $(10 \%$ de gordura) e reduziu entre T6 (10\% de gordura) e T9 ( $5 \%$ de gordura). A redução da dureza entre T6 $(10 \%$ de gordura e $10 \%$ de plasma) e T9 $(5 \%$ de gordura e $10 \%$ de plasma) está relacionada ao aumento do teor protéico (T6 $=15,37 \pm 0,06 \%$; $\mathrm{T} 9=17,47 \pm 0,22 \%)$ juntamente com a elevação da quantidade umidade (T6=67,55 $\pm 5,36 \% ; \quad T 9=74,25 \pm 0,94 \%$ ) (Tabela 3).

Como no perfil de textura, a força de cisalhamento é influenciada simultaneamente pelo teor de gordura e plasma adicionado, não sendo possível uma análise independente entre os fatores. Avaliando-se a Tabela 3, para o nível de $17 \%$ de gordura observou-se uma redução nos tratamentos $\mathrm{T} 1(10 \%$ de plasma) e T2 (5\% de plasma). Para $10 \%$ de gordura houve uma redução entre T4 ( $0 \%$ de plasma) e T6 $(10 \%$ de plasma), ao nível de $5 \%$ de gordura a redução significativa ocorreu entre T8 ( $5 \%$ de plasma) e T9 (10\% de plasma) e entre T7(ausência de plasma) e T9 (10\% de plasma). Houve um aumento significativo no teor de proteína total (Tabela 3) entre os tratamentos $\mathrm{T} 7(16,33 \pm 0,14 \%)$ e $\mathrm{T} 9(17,47 \pm 0,22 \%)$ o que contribuiu para a redução da força de cisalhamento. Os resultados encontrados corroboram com KHALIL (2000) que relatou decréscimo na força de cisalhamento em função da elevação da concentração do substituinte de gordura. Dentro dos níveis de plasma avaliados observou-se elevação dos valores de força de cisalhamento somente no nível de $5 \%$ de plasma nos tratamento T2 (17\% de gordura) e T5 (10\% de gordura). Segundo Troy, Desmond e Buckley (1999) hambúrgueres formulados com substituintes de gordura tais como fibras e proteínas do soro de leite apresentam força de cisalhamento menor, e a redução da força de cisalhamento está correlacionada a maior incorporação de 

gordura e plasma sanguíneo bovino

água que estes componentes não cárneos são capazes de proporcionar aos hambúrgueres de baixo teor de gordura. Keeton (1994) relata que uma textura mais macia dos hambúrgueres com menores teores de gordura é atribuída à substituição da gordura por água. Entretanto os níveis de plasma adicionados no presente estudo não foram suficientes para apresentar diferenças significativas nos tratamentos, porem os tratamentos T5 (10\% de gordura e $5 \%$ de plasma), T8 (5\% de gordura e $5 \%$ de plasma) e T9 (5\% gordura $+10 \%$ plasma) não apresentaram diferenças significativas nos teores e gordura e umidade como se observa na Tabela 3.

Diferentemente dos dados obtidos, Troy, Desmond e Buckley (1999) concluíram que hambúrguer com substitutos de gordura é significativamente mais macio que 0 controle, e que isto se deve ao aumento da capacidade de retenção de água do produto. Wong e Maga (1995) relatam que a dureza reduz com ou aumento do teor de gordura nos hambúrgueres. Isto se deve a ação lubrificante da gordura que facilita o processo de deglutição.

Analisando-se os valores de mastigabilidade e gomosidade variandose o plasma dentro de cada nível de gordura (Tabela 2), conclui-se que não houve diferenças significativas entre T1 ( $0 \%$ de plasma), T2 (5\% de plasma) e T3 (10\% plasma) para $17 \%$ de gordura, para $10 \%$ de gordura houve uma redução significativa destes atributos entre T4 (5\% de plasma) e T5 (10\% plasma), porem ao nível de $5 \%$ de gordura, ocorreu um aumento significativo nos valores de mastigabilidade e gomosidade entre T7 ( $10 \%$ de plasma) e T8 (5\% de plasma) e uma redução significativa entre T8 ( 5\% de plasma) e T9 (10\% de plasma). A mastigabilidade está relacionada à capacidade de formação de gel das proteínas. Geise (1992) afirma que a mastigabilidade e a elasticidade dos hambúrgueres com baixo teor de gordura foram melhoradas devido à natureza de gel do substituto de gordura utilizado. Entretanto, há estudos que indicam que as proteínas não cárneas podem atuar de forma negativa ou interferir na gelificação das proteínas miofibrilares da carne (Foegeding e Lanier, 1987). Hermansson (1982) relatou que as proteínas plasmáticas gelificam a uma temperatura acima das proteínas da carne e o fato das proteínas do plasma gelificarem mais tardiamente que as proteínas miofibrilares tornam o gel resultante da mistura mais fraco que o gel formado pelas proteínas musculares sozinhas. Este fato explica a instabilidade dos resultados da mastigabilidade e da gomosidade no presente estudo com o aumento das proteínas plasmáticas. Cofrades et al. (2000) investigaram o efeito da concentração das proteínas plasmáticas nas propriedades de textura de salsicha variando as proporções de gordura e observaram que altas concentrações de plasma favoreceram a formação de uma estrutura mais dura e com elevado valor de mastigabilidade.

Analisando-se 0 efeito da gordura dentro dos níveis de plasma (Tabela 2), observou-se que para $0 \%$ de plasma, ocorreu uma elevação nos valores de mastigabilidade e de gomosidade entre os T1 $(17 \%$ de gordura) e T4 (10\% gordura) e redução entre T4 (10\% de gordura) e T7 (5\% de gordura). A adição de $5 \%$ de plasma proporcionou elevação somente nos valores de mastigabilidade entre T5 ( $10 \%$ de gordura) e T8 (5\% de gordura), entretanto, não se observou diferenças entre T2 (17\% de gordura) e T5 (10\% de gordura) tanto para gomosidade como para mastigabilidade. A adição de 10\% de plasma proporcionou elevação nos índices de mastigabilidade e gomosidade entre T3 (17\% de gordura) e T6 (10\% de gordura) e redução entre 
T6 (10\% de gordura) e T9 $(5 \%$ de gordura) como se visualiza na Tabela 2.

Aleson-Carbonell et al. (2005) encontraram elevação nos valores de gomosidade utilizando albedo de limão como substituinte de gordura. As fibras criam uma rede tridimensional capaz de reter água e outros compostos que resultam na melhora da textura. As proteínas plasmáticas utilizam do mesmo princípio, apesar da conformação espacial, ligações intramoleculares e das propriedades físico-químicas serem distintas. Outro aspecto que os diferenciam é que as fibras e proteínas plasmáticas apresentam comportamentos reológicos distintos durante 0 processo de gelificação, o que interfere diretamente na qualidade sensorial dos alimentos, especialmente a textura (Borderías e Montero, 1988).

Considerando-se os valores de elasticidade (Tabela 2) observou-se que para $17 \%$ de gordura, houve diminuição da elasticidade com a adição de plasma, como se observa nos tratamentos $\mathrm{T} 1(0 \%$ de plasma) e T3 (10\% plasma), porem a adição de $10 \%$ de gordura proporcionou uma elevação deste atributo entre os tratamentos T4 (5\% de plasma) e T5 (10\% de plasma), já para $5 \%$ de gordura observou-se elevação significativa da elasticidade para os tratamentos T7 (10\% de plasma) e T8 (5\% de plasma) e redução entre T8 e T9.

A ausência de plasma proporcionou redução nos valores de elasticidade entre $\mathrm{T} 1$ (17\% de gordura) e T4 (10\% de gordura), a adição de $5 \%$ de plasma proporcionou uma elevação entre T5 (10\% de gordura) e T8 (5\% de gordura) e ao nível de $10 \%$ não houve variação da elasticidade com a redução dos níveis de gordura para os tratamentos T3 $(17 \%$ de gordura), T6 $10 \%$ de gordura) e T9 $(5 \%$ de gordura), o que contraria os resultados obtidos por Ulu (2006) que observou elevação dos valores de elasticidade em almôndegas ao se reduzir os níveis de gordura.

\section{CONCLUSÃO}

Conclui-se que o plasma apresentou melhoria das características de dureza, mastigabilidade, gomosidade e força de cisalhamento e pode ser utilizado como substituinte de gordura quando utilizado em determinadas concentrações em combinação com níveis de gordura reduzidos, visto que hambúrgueres com elevadas quantidades de gordura não apresentaram melhoria nas características estudas.

Os valores de elasticidade apresentaram dados contraditórios em função da gordura e plasma adicionados, entretanto nos tratamentos com elevada concentração de plasma, a gordura não exerce um papel significativo.

\section{REFERÊNCIAS}

ABIOLA, S. S.; ADEGBAJU, S. W. Effect of substituting pork back fat with rind on quality characteristics of pork sausage. Meat Science, v.58, p. 409-412, 2001.

ALESON-CARBONELL, L.; FERNÁNDEZLÓPEZ, J.; PÉREZ-ALVAREZ, J. A.; KURI, V. Characteristics of beef burger as influenced by various types of lemon albedo. Innovative Food Science \& Emerging Technologies, v.6, n.2, p.247-255, 2005.

ASSOCIATION OF OFFICIAL ANALYTICAL CHEMISTS (AOAC). Official methods of analysis. 18. ed.: Crude protein in meat and meat products, cap. 39, p. 6-7, met. 992.15, 2007a.

ASSOCIATION OF OFFICIAL ANALYTICAL CHEMISTS (AOAC). Official methods of analysis. 18. ed.: Fat crude in meat and meat products - solvent extraction, cap. 39 , p. 3, met. 991.36, 2007b.

ASSOCIATION OF OFFICIAL ANALYTICAL CHEMISTS (AOAC). Official methods of 

gordura e plasma sanguíneo bovino

analysis. 18. ed.: Moisture in meat, cap. 39, p. 1, met. 950.46, 2007c.

\section{ASSOCIATION OF OFFICIAL ANALYTICAL CHEMISTS (AOAC). Official methods of analysis. 18. ed.: Ash of meat, cap. 39, p. 4, met. 920.153, 2007d.}

BORDERÍAS, A. J.; MONTERO, P. Fundamentos de la funcionalidad de las proteínas em alimentos. Revista Agroquímica y Tecnologia de Alimentos, v.28, n.2, p.159-169, 1988.

BRASIL. Instrução Normativa n²0. DOU de 21.07.1999.

COFRADES, S.; GUERRA, M. A.; CARBALLO, J. et al. Plasma protein and soy fiber content. Effect on bologna sausage properties as influenced by fat level. Journal of Food Science, v.65, n.2, p.281-287, 2000 .

CRENWELGE, D. D.; DILL, C. W.; TYBOR, P. T. et al. A comparison of emulsification capacities of some protein concentrates. Journal of Food Science, v.39, n.1, p.175-177, 1974.

DEL HOYO, P.; RENDUELES, M.; DÍAZ, M. Effect of processing on functional properties of animal blood plasma. Meat Science, v.78, n.4, p.522-528, 2008.

DUARTE, R. M. T.; SGARBIERI, V. C. Propriedades tecnológicas das frações protéicas de sangue bovino: Plasma e Globina. Braz. J. Food Technol., v.3, n.1, p.23-30, 2000.

FOEGEDING, E. A.; LANIER, T. C. The contribution of nonmuscle proteins to texture of gelled muscle protein foods. Cereal Foods World, v.32, p.202-205, 1987.

GEISE, J. Developing low-fat meat products. Food Technology, v. 46, n.4, p.100-108, 1992.

GUZMAN, J. C.; MCMILLIN, K. W.; BIDNER, T. D.et al. Texture, color and sensory characteristics of ground beef patties containing blood proteins. Journal of Food Science, v 60, p.657-660, 1995.

HERMANSSON, A. M. Gel characteristicsstructure as related to texture and waterbinding of blood plasma gels. Journal of Food Science, v.47, n.3, p.1965-1972, 1982.

JIMÉNEZ-COLMENERO, F. Technologies for developing low-fat meat products. Trends in Food Science \& Technology, v.7, n.2, p.41-48, 1996.
KEETON, J. T. Low-fat meats products technological problems with processing. Meat Science, v.36, n.1/2, p.261-276, 1994.

KHALIL, A. H. Quality characteristics of low-fat beef patties formulated with modified corn starch and water. Food Chemistry, v.68, p.61-68, 2000.

KUMAR, M.; SHARMA, B. D. The storage stability and textural, physico-chemical and sensory quality of low-fat ground pork patties with carrageenan as fat replacer. International Journal of Food Science and Technology, v.39, n.1, p.31-42, 2004.

MINITAB Release 16 for Windows $\AA$. < http://www.minitab.com/pt-BR/default.aspx> , Disponível em 13/04/2012, acesso 13/04/2012.

PENTEADO, M. D. V. C.; LAJOLO, F. M.; SANTOS, N. P. Functional and nutrional properties of isolated bovine blood proteins. Journal of Agricultural and Food Chemistry, v.30, n.8, p.809-815, 1979.

SAGUER, E.; ALVAREZ, P.; SEDMAN, J. et al. Heat-induced gel formation of plasma proteins: New insights by FTIR 2D correlation spectroscopy. Food Hydrocolloids, v.23, n.3, p.874-879, 2009.

TOBITANI, A.; ROSS-MURPHY, S. B. HeatInduced Gelation Globular Proteins. I. Model for effects of time and temperature on the gelation time of BSA gels. Macromolecules, v.30, n.17, p.4845-4854, 1997.

TROY, D. J.; DESMOND, E. M.; BUCKLEY, D. J. Eating quality of low-fat beef burger containing fat-replacing functional blends. J. Sci. Food Agric., v.79, p.507-516, 1999.

ULU, H. Effects of carrageenam and guar gum on the cooking and textual properties of low fat meatballs. Food Chemistry, v.95, p.600-605, 2006.

VANDENDRIESSCHE, F. Meat products in the past, today and in the future. Meat Science, v.78, n.1/2, p.104-113, 2008.

VIANA, F. R.; SILVA, V. D. M.; DELVIVO, F. M. et al. Quality of ham pâté containing bovine globin and plasma as fat replacers. Meat Science, v.70, p. 53-160, 2005.

WONG, N. H.; MAGA, J. A. The effect of fat content on the quality of ground beef patties. Developments in Food Science, v.37, p.13451351, 1995. 